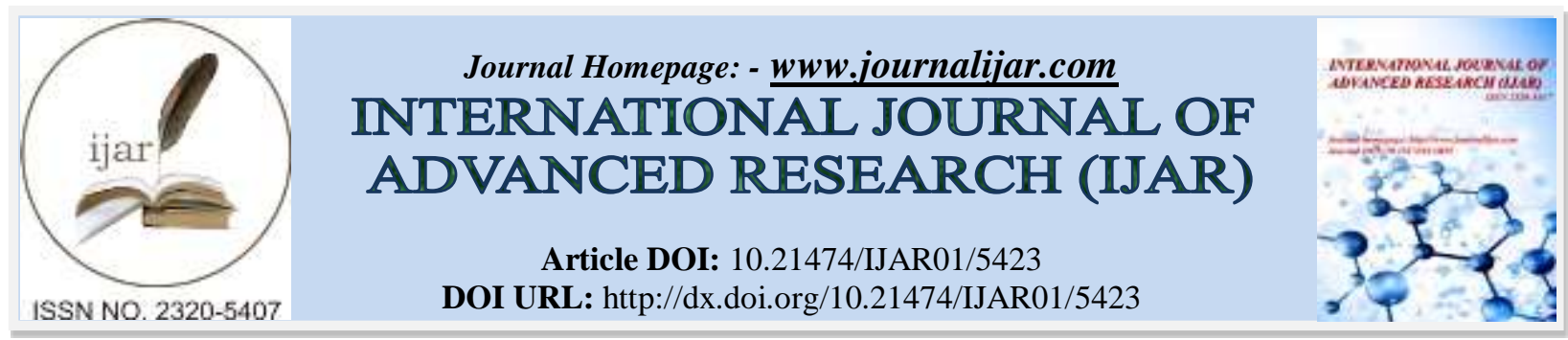

RESEARCH ARTICLE

\title{
CASE STUDY OF GASTRO-OESOPHAGEAL REFLUX DISEASE (GERD) V/ S MIGRAINE: DO THEY MINGLE OR IS IT A MYTH.
}

\author{
Dr. Sphoorthi Basavannaiah M.S (ENT). \\ Assistant Professor, Department Of ENT, Subbaiah Institute Of Medical Sciences, NH-13, Purle, Holebenavalli \\ Post, Shimoga-577222, Karnataka, India.
}

\section{Manuscript Info}

Manuscript History

Received: 13 July 2017

Final Accepted: 15 August 2017

Published: September 2017

Key words:-

GERD, Migraine, Lifestyle modification.

\begin{abstract}
Introduction: Over the years, there has been a dilemma regarding arriving at a diagnosis for headache pertaining to its variety of causes. One of the most common overlooked cause in the present day scenario for headache is GERD and Migraine. On day to day basis, we come across varied patient symptomatology which has indeed made us give a second thought to prescribe on management.

Aim and Objective: To study if GERD and Migraine actually co-exist or they have a separate root cause for headache and also how change in lifestyle has an impact on health.

Methodology: A study of random sample of 450 patients was conducted based on clinical evaluation for diagnosis and conservative management for the same was advised emphasising particularly on lifestyle modification.

Results: The results drawn were compared by tabulating them into 3 groups with the two conditions taken as a separate entity and third when the two being mingled to conclude if interlink exists between the two conditions or purely is it a myth.

Conclusion: Intermingling of GERD and Migraine was noted predominantly in our study rather than their separate existence.
\end{abstract}

Copy Right, IJAR, 2017,. All rights reserved.

\section{Introduction:-}

Headache, has now become one of the most common presentation at our outpatient department due to frantic regime in our present day scenario. As per WHO, majority of adults worldwide will experience headache in a year at some point or the other in their life. It can affect anyone regardless of age and gender. Headaches can be primary due to overactivity of pain-sensitive areas like nerves, blood vessels and muscles of head and neck or due to changes in chemical activity of brain in cases of Migraines and secondary due to conditions that stimulate the pain- sensitive areas as in GERD. Due to our hectic daily schedule and desire to have a lavish lifestyle; we often overlook upon simple sources of headache and put our minds into discerning and directing over rare origins of headache. By shifting the focus to merely adapting modest, easy and applicable lifestyle measures; most of the basic concerns of headache can be sorted. This is the reason behind selecting this topic for the study.

\section{Aims and Objectives:-}

To study synergism between GERD and Migraine.

To study if there is superimposition existing between GERD and Migraine. 
To study if lifestyle modification has a role to play in recovery of patients.

\section{Methodology:-}

A prospective study was conducted among a random sample of mixed spectrum of 450 patients with headache as their presentation over a period of 3 months. All were analytically questioned to find out the genesis of their presentation. They were clinically evaluated to arrive at a precise diagnosis and apt management was prescribed and were followed up at the intervals of 15 days, 30 days, 45 days, 60 days and $>90$ days. The observed results are pictorially represented below.

\section{Inclusion criteria:-}

Only patients with GERD and Migraine are included in the study as causes of headache.

No gender bias.

Only adults were included in the study.

\section{Exclusion criteria:}

All other causes of headache are excluded from the study.

Children were excluded from the study.

\section{Results:-}

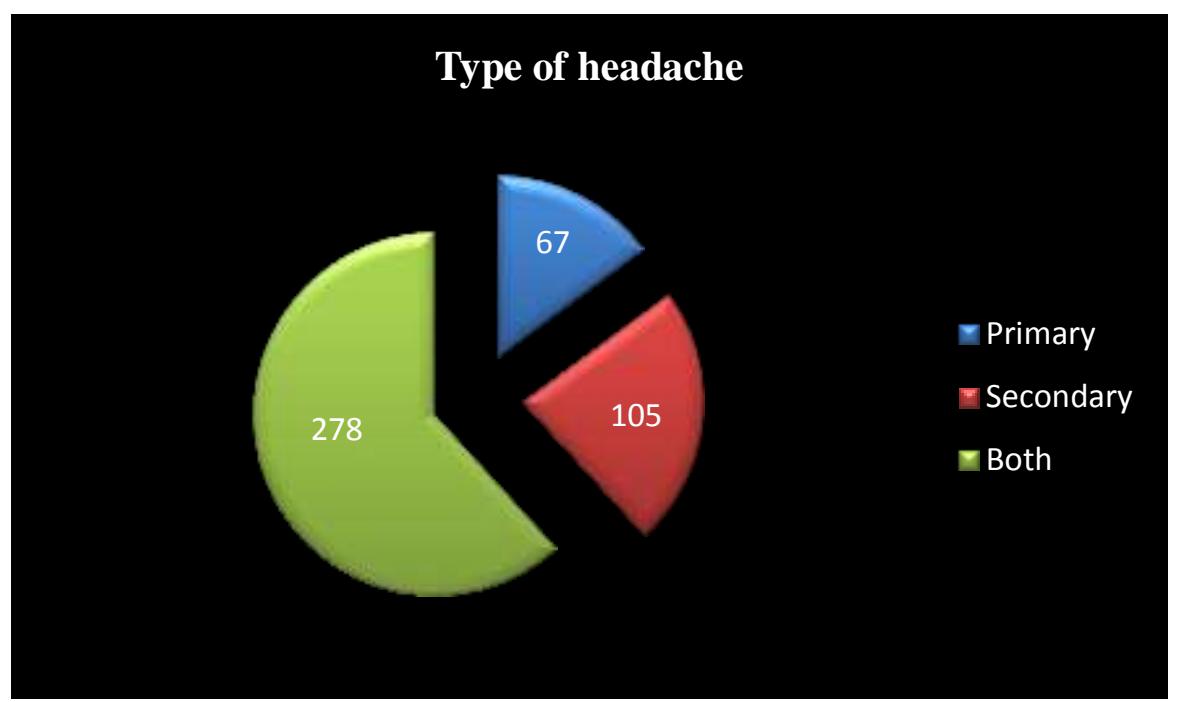

Figure 1:- 'Pie diagram' showing the type of headache among the sample size. Among which 278 of them had combined primary + secondary headache. While second in the row were 105 of them with GERD and the remaining 67 of them with Migraine. 


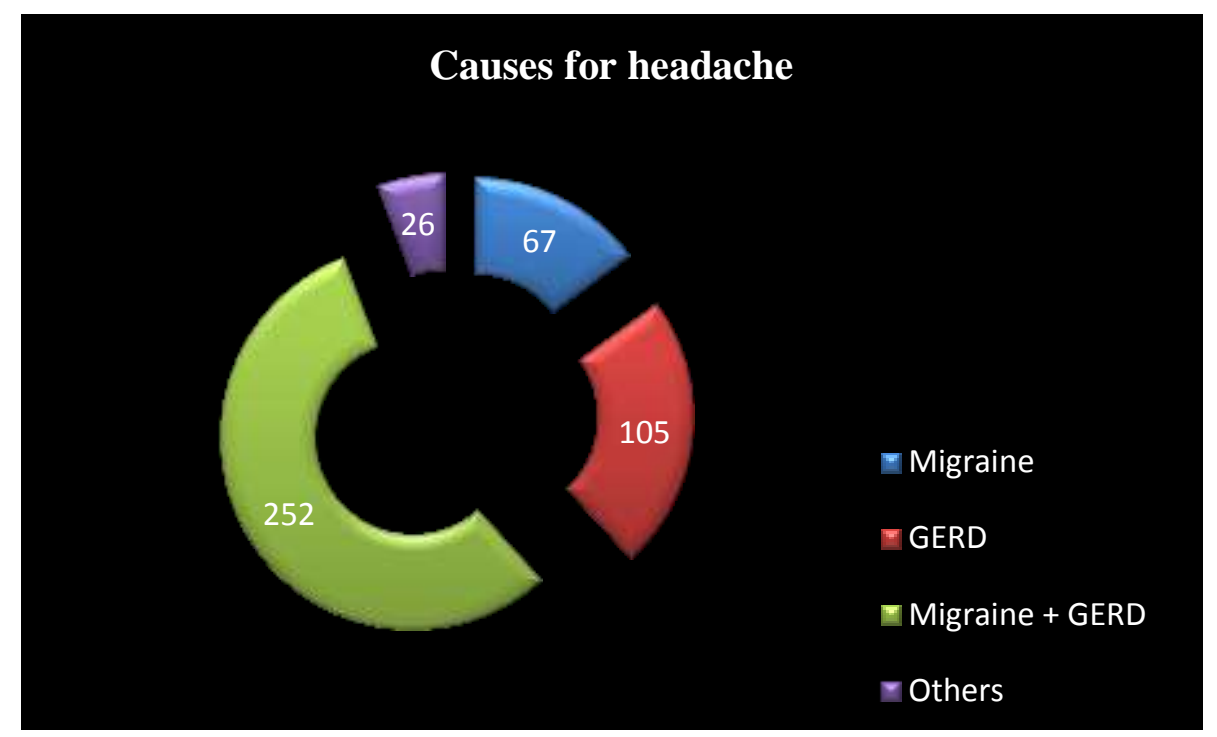

Figure 2:-'Doughnut graph' showing the causes for headache. Among the sample size, 252 of them presented with both Migraine+ GERD. Around 105 of them presented with only GERD and 67 of them presented with Migraine only. Rest, 26 of them presented with other causes of headache.

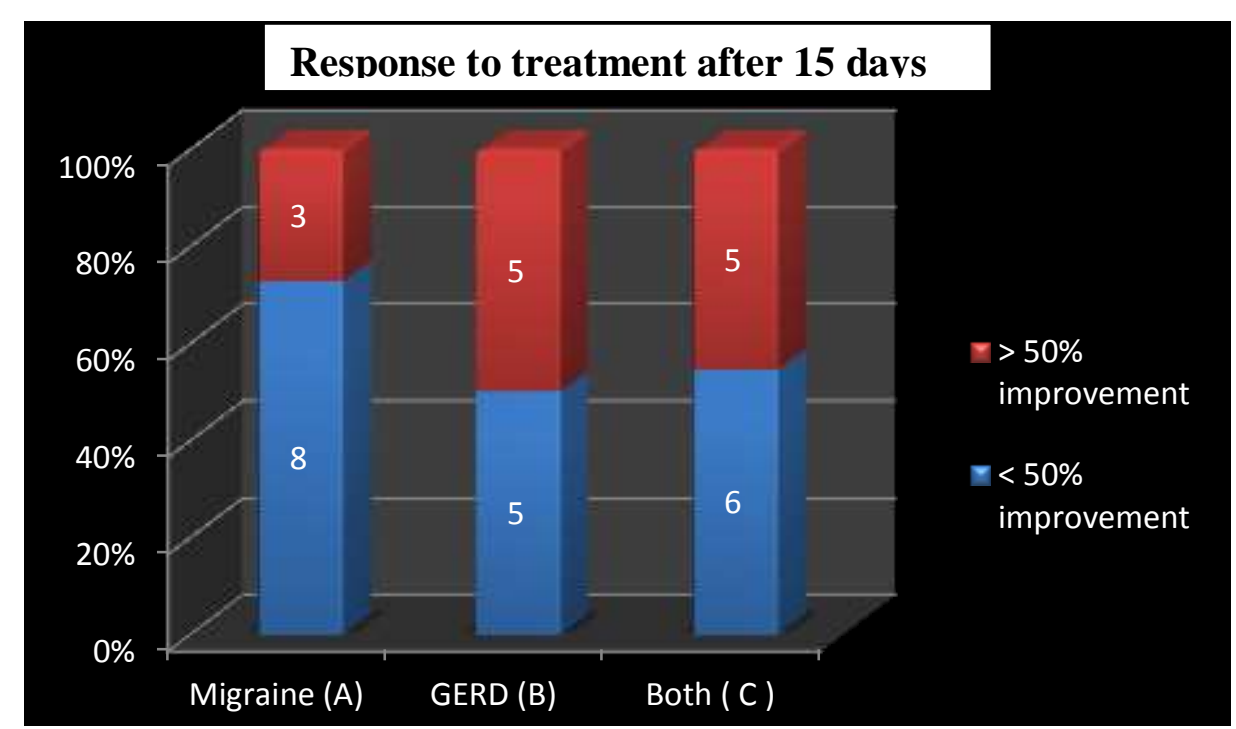

Figure 3:- 'Stacked column in 3D' graph showing response to treatment of patients after a follow-up of 15 days. Among Group A with 11 patients, 8 showed $<50 \%$ improvement and 3 showed $>50 \%$ improvement. 10 patients of Group B were followed up, of which 5 showed $<50 \%$ improvement and 5 showed $>50 \%$ improvement. Among the rest 11 patients of Group C, 6 showed < 50\% improvement and 5 showed $>50 \%$ improvement. 


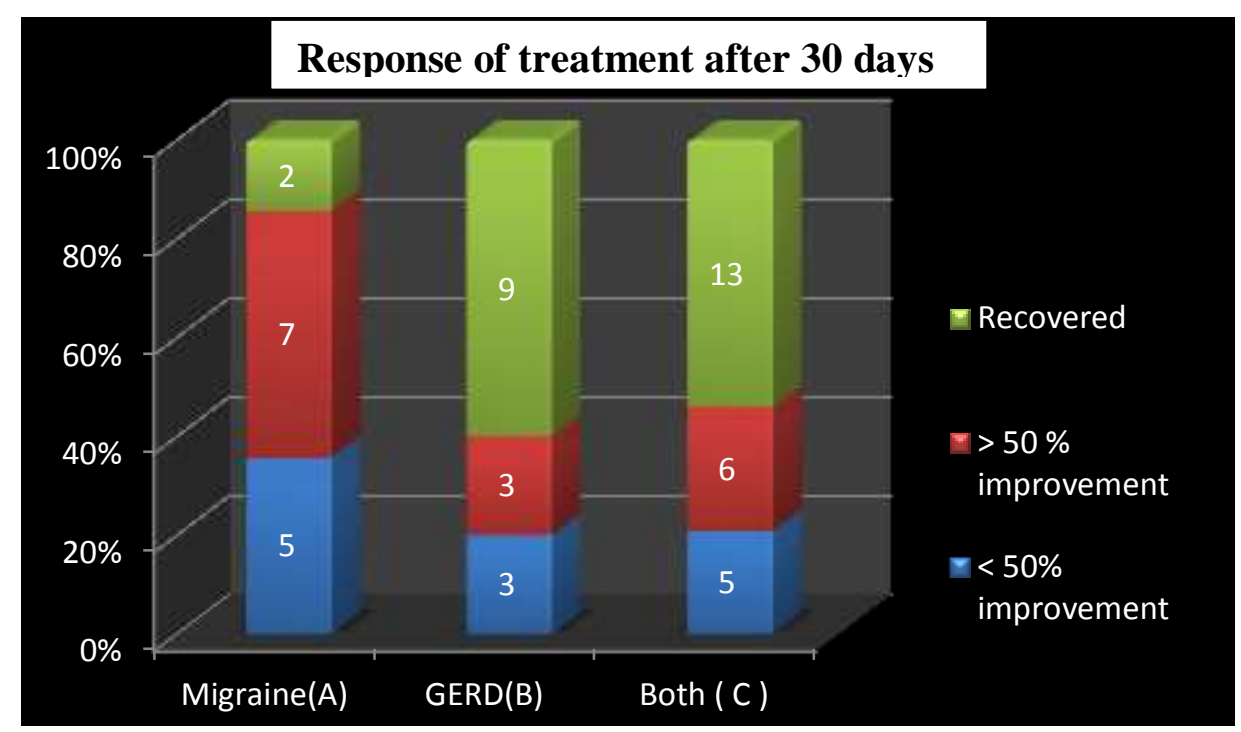

Figure 4:- 'Stacked column in 3D', graph showing response to treatment of patients after a follow up of 30 days. Among 14 patients in Group A, 5 showed $<50 \%$ improvement and 7 showed $>50 \%$ improvement and 2 were fully recovered. 15 patients in Group B were followed up, among whom 3 showed $<50 \%$ improvement and 3 showed $>$ $50 \%$ improvement and 9 showed full recovery. The rest 24 patients of Group C, 5 showed $<50 \%$ improvement and 6 showed $>50 \%$ improvement and 13 were fully recovered.

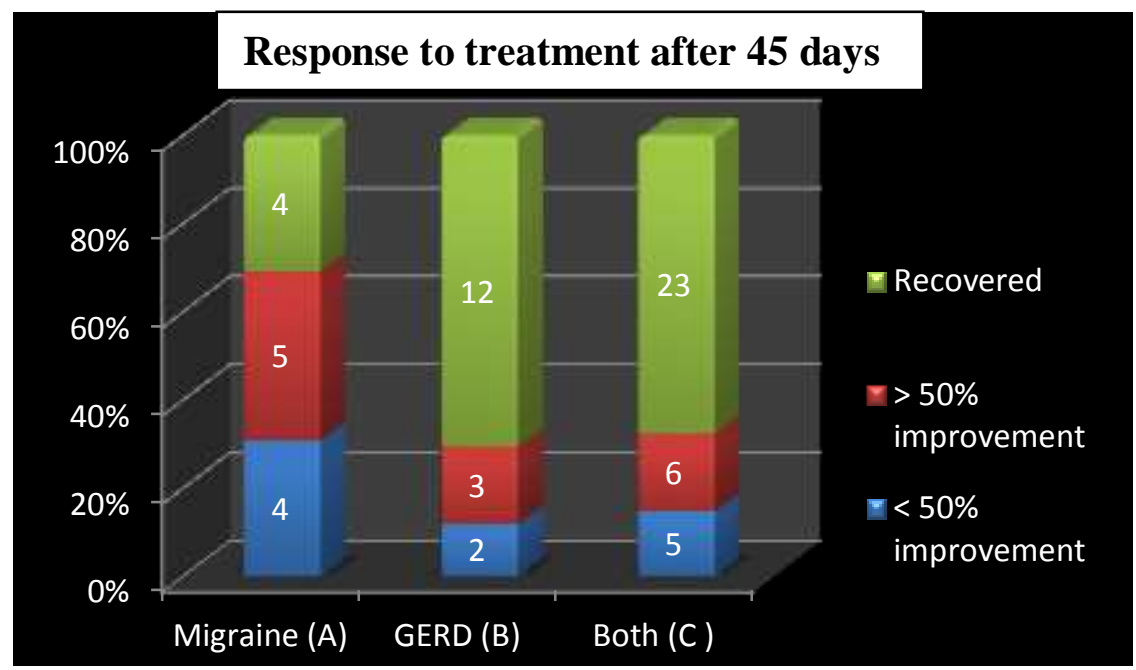

Figure 5:- 'Stacked column in 3D', graph showing response to treatment of patients after a follow up of 45 days. 13 patients under Group A, 4 showed $<50 \%$ improvement and 5 showed $>50 \%$ improvement and 4 were fully recovered. 17 patients of Group B were followed up, of which 2 showed $<50 \%$ improvement and 3 showed $>50 \%$ improvement and 12 showed full recovery. Among 34 patients under Group C, 5 showed $<50 \%$ improvement and 6 showed $>50 \%$ improvement and 23 were fully recovered. 


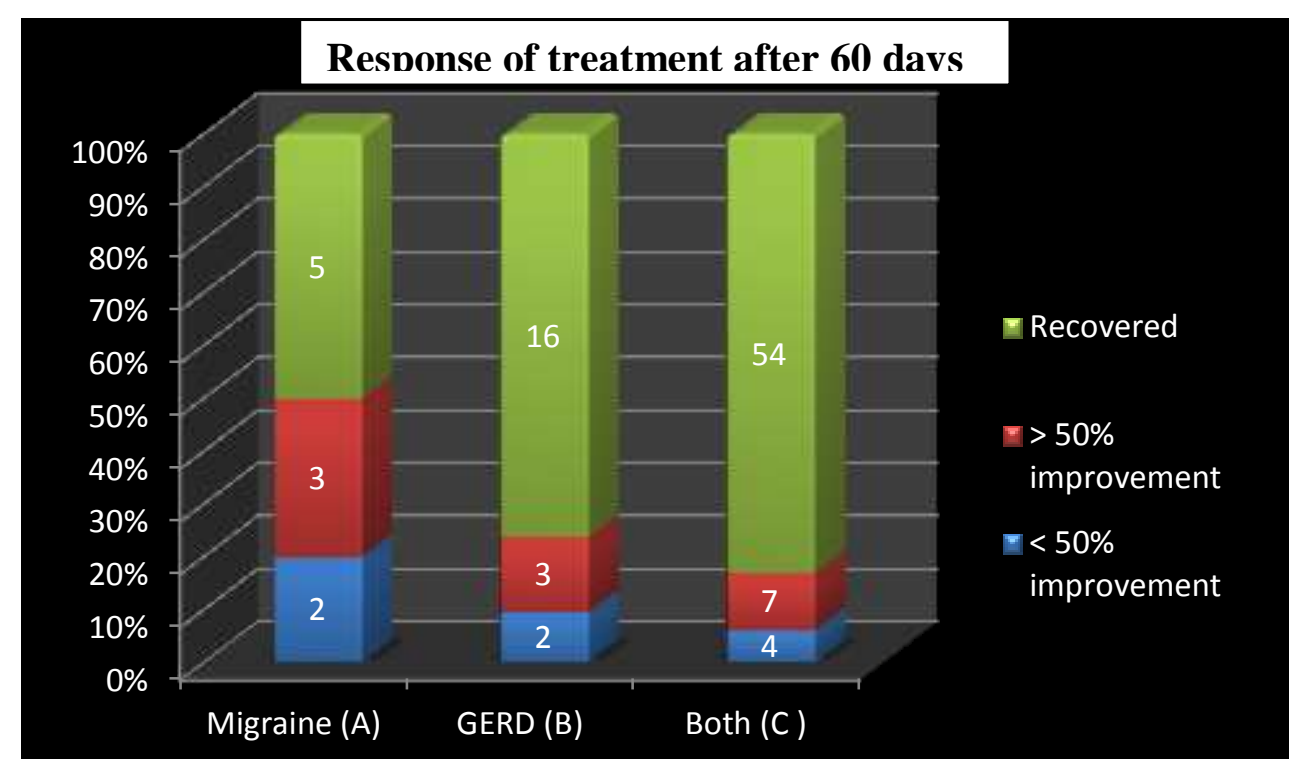

Figure 6:-'Stacked column in 3D', graph showing response to treatment of patients after a follow up of 60 days. 10 patients under Group A, 2 showed $<50 \%$ improvement and 3 showed $>50 \%$ improvement and 5 were fully recovered. 21 patients under Group B were followed up, among them 2 showed $<50 \%$ improvement and 3 showed $>50 \%$ improvement and 16 showed full recovery. Among 65 patients under Group C, 4 showed $<50 \%$ improvement and 7 showed $>50 \%$ improvement and 54 were fully recovered.

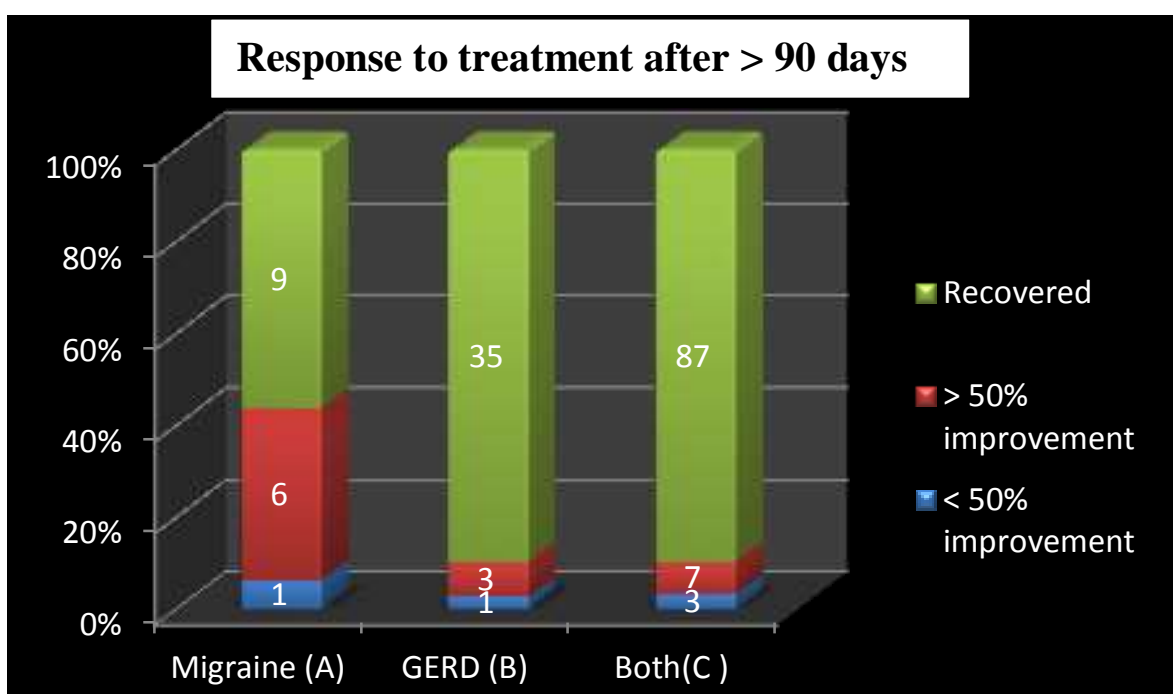

Figure 7:- 'Stacked column in 3D', graph showing response to treatment of patients after a follow up of $>90$ days. Of 16 patients under Group A, 1 showed $<50 \%$ improvement and 6 showed $>50 \%$ improvement and 9 were fully recovered. 39 patients under Group B were followed up, among whom 1 showed $<50 \%$ improvement and 3 showed $>50 \%$ improvement and 35 showed full recovery. Among 97 patients under Group C, 3 showed $<50 \%$ improvement and 7 showed $>50 \%$ improvement and 87 were fully recovered. 


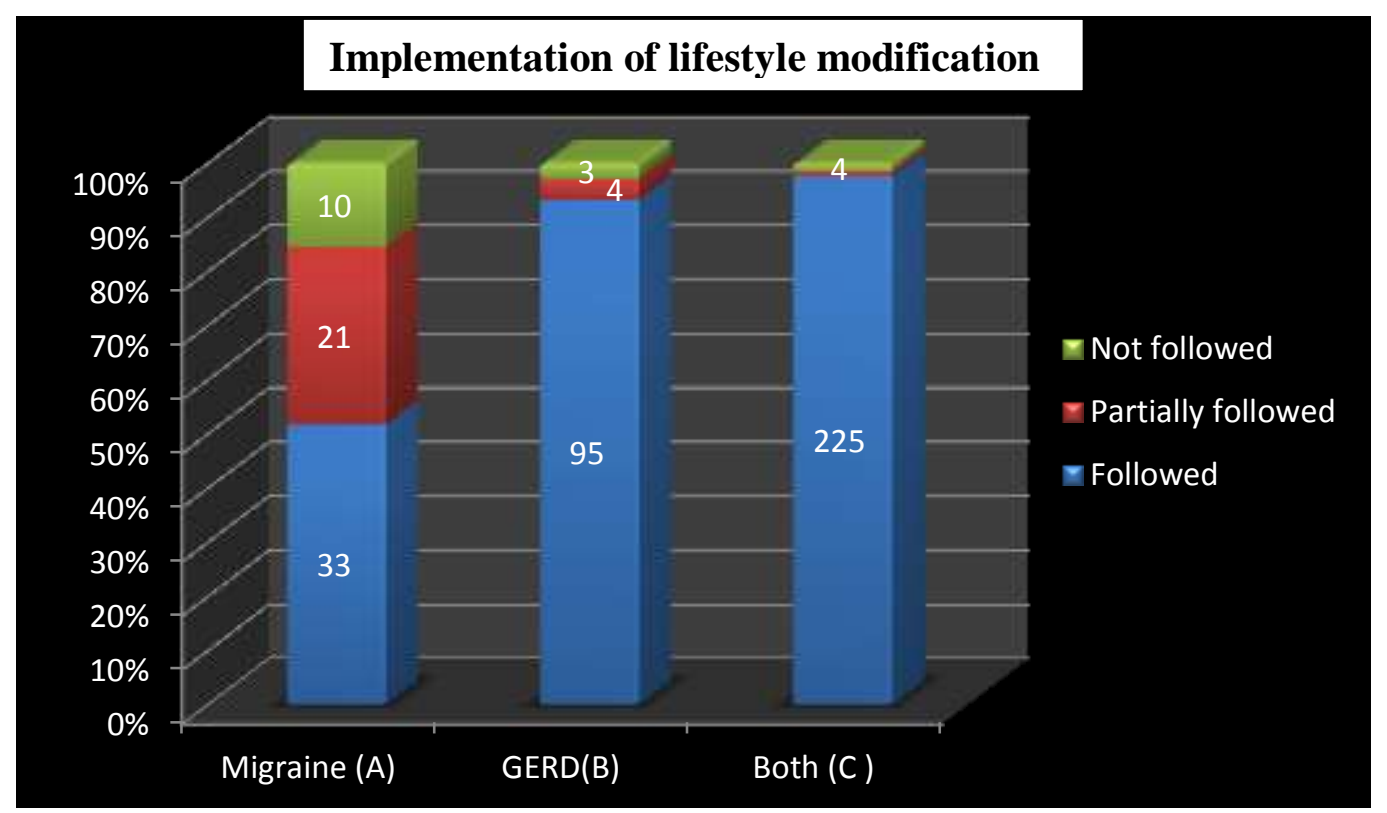

Figure 8:- 'Stacked column in 3D' graph showing how many patients have implemented the changes in their lifestyle on daily basis. In Group A, 33 of them have followed the suggested lifestyle measures, while rest 21 have implemented partially and 10 have not followed any measures. While in Group B, majority of 95 patients have followed the lifestyle measures among a total of 102 patients, while the rest 4 of them have partially implemented and the remaining 3 have not followed. In Group C, almost all of about 225 patients have actually implemented the lifestyle changes in their daily routine while the remaining 6 , among which 2 have partially followed and 4 have not followed the lifestyle measures.

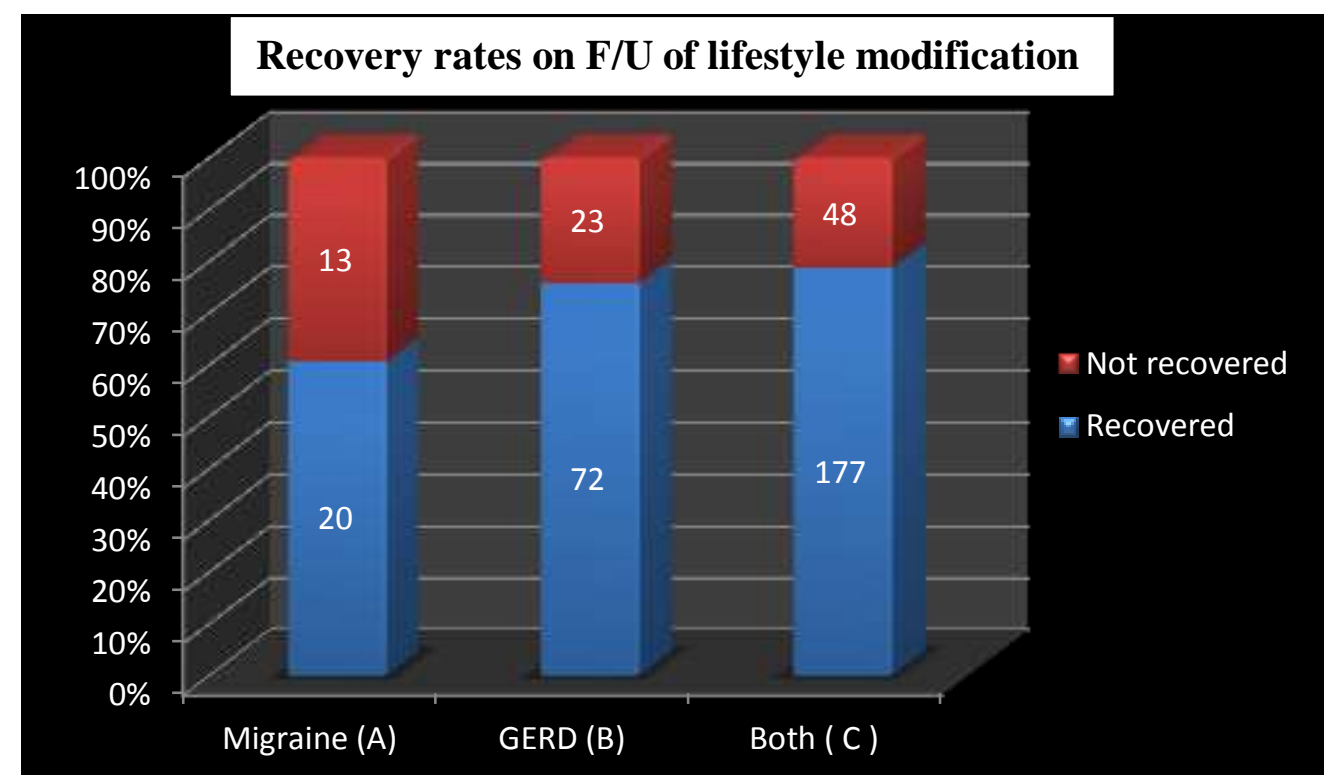

Figure 9:- 'Stacked column in 3D' graph shows the recovery rates attained after following the lifestyle measures. In Group A, out of 33 patients, 20 of them showed complete recovery with lifestyle modifications and 13 of them did not show any recovery. But in Group B with 95 patients, 72 of them totally recovered and rest 23 showed no signs of recovery. But major results were attained in Group C with 225 patients, wherein 177 of them showed positive response to recovery while the remaining 48 did not recover.

\section{Discussion and Conclusions:-}

There are so many innumerable and infinite changes happening with each passing day or must say every single second in our life, that it seems quite complicated to lead a normal simple existence. The only criteria each one of us 
wish for in the present day scenario is to mint money and lead a luxurious lifestyle no matter what say ${ }^{(4,32)}$. In this rat race to make money, we often tend to neglect our health or realistically overlook upon it in order to fulfil our goals and desires of life ${ }^{(1,6,20)}$. In this game of snake and ladder called life, we want to achieve the impossible and attain greater heights in no time at the cost of biggest gift given to us by nature called health. During this process of touching the skies, an infinite amount of stress gets developed within us, which outbursts as headache. As there goes an ancient and popular saying, "Health is Wealth", but the present situation has become vice versa ${ }^{(4,9,13)}$.

Nowadays, headache has become one of the most common complaint patient comes up with at our outpatient set-up due to uptight regime in our present day setting. Based on the literature analysis over the years, WHO recently has come up with the statement that majority of adults worldwide experience headache in a year at some point of time ${ }^{(5,17)}$. It can affect anyone regardless of age and gender. Over the years, there has been impasse regarding diagnosis for headache concerning to its various causes ${ }^{(11,23,40)}$. GERD and Migraine are considered to be one of the most neglected cause in the present scenario. On daily basis, we come across numerous patient issues regarding the same concern, which has indeed made us give a second thought to arrive on pertinent management ${ }^{(16,22,36)}$.

Health care providers spend a lot of time dealing with headache patients, where there is worry over secondary causes for headache such as GERD. But the great majority of time is spent managing patients with primary headache such as Migraine. Headaches can be primary due to overactivity of pain-sensitive areas like nerves, blood vessels and muscles of head and neck or due to changes in chemical activity of brain in cases of Migraines and Secondary due to conditions that stimulate these pain- sensitive areas as in GERD ${ }^{(3,17,42)}$.

Gastro-esophageal reflux disease is a very common condition affecting $>30 \%$ of people in their life. Heartburn is a condition in which gastric contents regurgitate and irritate the oesophagus. After every reflux, there is a peristaltic wave in oesophagus which clears the gastric contents ${ }^{(16,33)}$. Almost $20 \%$ of adults complain of atleast 1 episode of heartburn/week and about $10 \%$ of them complain of daily episode of heartburn due to various trigerring factors mainly stress and sedentary lifestyle ${ }^{(8,14,45)}$.

Migraine is a disabling neurologic condition that affects $2 \%$ of the general population. Patients with chronic migraine have headaches on at least 15 days a month, with at least 8 days a month on which their headaches meet up with associated symptoms ${ }^{(23,36)}$. Chronic migraine places an enormous burden on patients owing to frequent headaches with aura and typically develops after a slow increase in headache frequency over months to years ${ }^{(10 \text {, }}$ $19,41)$.

Though knowing both the pros and cons of both the conditions, as per the study; following evaluation of patients were done. Based on the observations made in the study, subsequent conclusions were drawn:

Majority of the patients with headache who were consulted on outpatient set-up, had a combination of both types of headache that is Primary and Secondary headache (278). Among the remaining patients, the type of headache was mainly Secondary (105) rather than Primary (67), as depicted in Figure 1. These findings coincide with the Aim and Objectives of the study ${ }^{(5,18,26,47)}$.

On further evaluation of patients, the causes of headache was arrived at. Nearing 6\% (26) of the patients of the sample size had other causes for headache which was excluded from the study. 56\% (252) of the sample size were suffering from the combination of GERD and Migraine. The rest, about 23\% (105) of the sample had GERD as the cause for headache and nearing 15\% (67) had Migraine as their cause of headache, as shown in Figure 2. This fact also once again proves that there is a strong interlink existing between GERD and Migraine and superimposition of GERD over Migraine ${ }^{(2,15,33,46)}$.

All the patients were then advised management in the form of oral medications and lifestyle modifications. Below mentioned are the conservative line of treatment advised to the patient.

\section{GERD:-}

Tablet. Pan-D (combination of proton-pump inhibitor PANTOPRAZOLE and DOMPERIDONE peripherally selective dopamine D2 receptor antagonist), Syrup. Mucaine $200 \mathrm{ml}$ gel (Local anaesthetic liquid which contains Aluminium hydroxide, Magnesium Hydroxide and Oxetacaine) and Vitamin supplements. 


\section{Migraine:-}

Tablet. Sibelium 10mg 1 HS ( FLUNARIZINE Calcium antagonist), Tablet Pan-D(combination of proton-pump inhibitor PANTOPRAZOLE and DOMPERIDONE peripherally selective dopamine D2 receptor antagonist), Tablet Dolo 650mg( PARACETAMOL) 1 SOS.

\section{Lifestyle modifications for GERD and Migraine:-}

1. To avoid food stuffs like chocolates, and dairy products corn, egg whites, caffeine, avocado, corn, seafood, citrus fruits, tea, soda, onion, sugary foods, artificial sweeteners and colors.

2. Avoid change of weather quite often (hence dress in layers to adjust to temperature changes) - for Migraine.

3. Usage of sunglasses (for photophobia) - for Migraine.

4. Usage of headphones/ earplugs (for phonophobia) - for Migraine.

5. Usage of antiglare screens on desktop/laptops- for Migraine.

6. Usage of right light bulb- for Migraine.

7. Avoid motion sickness.

8. Sit in the front seat of car preferably.

9. If chances of woozy while watching 3D movies, skip the glasses.

10. Try and avoid stress as much as possible.

11. To relieve from stress- relax with meditation, yoga and divert focus on one task at a time.

12. Exercise 30 minutes 3 times/ week for de-stress.

13. Usage of mouth guard to reduce stress on jaw.

14. Try to avoid unnecessary medications.

15. Preferably do not read in car.

16. Sleep for adequate of 7-8 hours of sleep (have a regimented sleep pattern and do not lie in a weekend).

17. Do not skip meals, fast or diet and eat frequent not more than 3 hours of gap.

18. Avoid bruxism, clenching teeth, chew more gum, take small bites in intervals and eat mints instead of gum.

19. Do not hunch back and be more aware of posture.

20. Use fresh fruits and vegetables (avoid frozen foods).

21. To lose weight (obesity is directly proportional to migraine).

22. Think positive and relax with massage, painting to rejuvenate mind- for Migraine.

23. On rest, provide inclination towards head end (15-30 degree) - for GERD.

24. Eat less spicy/oily/sour and hot foods- for GERD.

25. Do not sleep immediately after consuming food- for GERD.

26. Avoid alcohol and smoking- for both.

27. Avoid tight fitting garments -for GERD.

28. Prefer dietary fibres and natural sugars.

The response to treatment prescribe to the patients were followed up over a period of 15 days which are as followsConsidering the chronicity of these conditions, $\mathbf{1 5}$ days is a very short duration to conclude on recovery rates. No effective response to treatment was noted with Group A, as duration of its treatment is inclined towards prophylaxis on a long run. The rest 2 groups almost showed neck to neck response rates. In a total of 32 patients who were followed up after a fortnight, 13 patients $(41 \%)$ have shown $>50 \%$ improvement to treatment as depicted in Figure $3^{(7,12,25,43)}$

As shown in Figure 4, with increase in days of follow-up, response rates to treatment as well as number of patients both showed an increasing trend. But this change, of increase response to treatment is only noted with Group B and C. Among the 3 groups, Group $\mathrm{C}$ tops the list in terms of response rates after a period of 1 month. Out of 53 patients who followed up, 24 patients (nearly 45\%) gave a feedback of complete recovery, with emphasis of introducing simple lifestyle modifications in their day to day life. This in a way is proving that assumptions made in the study holds good with the data ${ }^{(21,29,37,44)}$.

Over a period of $\mathbf{4 5}$ days of follow up, number of patients with their response to treatment has significantly raised. Among a total of 64 patients, almost $61 \%$ (39 patients) have shown total recovery, which is positive indication that the patients are very well responding to the treatment prescribed for their wellbeing. $>65 \%$ showed good recovery rates in Group B and C. Following patient feedback, they are all content with certain modifications undertaken by them on daily basis has proved beneficial from a health point of view and also is playing a role in improving the cause behind the treatment. Even, this data coincides with the conventions made in the study as per Figure $\mathbf{5}^{(24,31,38)}$. 
On a follow up of 2 months, among a total of 96 patients, $78 \%$ (75 patients) are giving a good response to conservative management with a higher percentage of improvements seen in Group B and specifically Group C. This also indirectly indicates that, management measures advised to the patients are very well undertaken by them with after explaining to them regarding the pros and cons of the condition. This is not only shows in the amount of follow up but also the response to treatment. As per the data representation in Figure 6, the assumptions made for the study are being proven ${ }^{(27,32,39)}$.

After a follow up of > 3 months, 131 patients among 152 of them showed major recovery rates, that is almost $86 \%$. This progress is mainly seen in Group C, where among 97 patients 87 of them showed good response to treatment and in Group B, of 38 patients good rates of recovery following treatment prescribed to in 35 patients. The suppositions set up at the beginning of the study are being established right with every passing facts that are tabulated in terms of response to management as described in Figure $7^{(30,34)}$.

Out of 397 patients who were advised lifestyle modifications to be undertaken as a part of their daily set-up, 353 religiously followed them. This shows that more than majority $(89 \%)$ followed up judiciously which indicates that advised lifestyle changes in patient's daily monotonous life has brought in gross impact their well- being. Around 27 of them (7\%) have tried to inculcate these simple measures in their routine partially and could not follow it for reasons unknown while the rest 17 of them (4\%) agreed to the fact that they had followed any measures during the course of treatment and is well shown in Figure 8. Hence, this data provided above also holds good with the objectives undertaken in this study ${ }^{(28,35)}$.

As depicted in Figure 9, 353 patients were evaluated on the basis of implementation of lifestyle measures and recovery rates were accounted. Of them, 269 showed good response with recovery rates of $76 \%$. This shows that inculcating good and practical lifestyle measures has fetched good results in terms of good recovery response. While $24 \%$ (84) patients did not recover with only modifications of lifestyle, as they required oral medications also to show response to treatment. Once again, this tabulation in a way proves the aim that was taken up during the course of the study ${ }^{(13,29)}$.

The following conclusions were drawn from the study which are as follows: The combination of primary and secondary headache takes the top spot in occurrence, while secondary headache takes the second place in existence among the total sample size of 450 patients with headache. Hence, indicating that secondary cause for headache as a single factor or in combination predominates primary cause of headache. As it is known that, overactivity of pain sensitive areas in the brain are the root cause for migraine but stimulation of these areas, is the origin for GERD. This indeed is the proof that GERD superimposes Migraine. With further evaluation, patients with GERD and Migraine had a majority of population while only GERD was second in the line for the cause of headache among the sample size. 26 were excluded from the study due to presence of other causes of headache. This fact once again proves that there is a strong synergism and interlink existing between GERD and Migraine and also superimposition of GERD over Migraine. All the patients were treated conservatively with particular focus on lifestyle modifications. These patients were then followed over a period of 3 months at different intervals to know their response to treatment with combination of oral medications and lifestyle changes and how implementing the prescribed routine lifestyle measures has brought in the brighter side of health improvement in their lives. Out of 424 patients who were followed up, 27 of them were excluded from the sample size that is 14 of them were refractory to treatment measures advised to them and 13 due to non-follow up. Based on follow up over 3 months, following observations were noted in the study which are-

1. There is a strong association and intermingling of GERD with Migraine moreover GERD superimposes Migraine in both occurrence and existence. Hence it is not a myth, as they are found to actually co-exist.

2. Lifestyle modification is directly proportional to response and recovery of the conditions over oral medications and has brought in good results in the study, that is more than $75 \%$.

3. Implication of lifestyle modification has not only resolved the disease conditions but also has brought in a new change in the outlook to approach and tackle these effects on a daily basis. 


\section{References:-}

1. Pinessi L, Savi L, Pellicano R, Rainero I, Valfrè W, Gentile S, Cossotto D, Rizzetto M, Ponzetto A (2000): Chronic Helicobacter pylori infection and migraine: a case-control study. Headache.; 40:836-839.

2. Voutilainen M, Sipponen P, Mecklin JP, Juhola M (2000): Gastroesophageal reflux disease: prevalence, clinical, endoscopic and histopathological findings in 1128 consecutive patients referred for endoscopy due to dyspeptic and reflux symptoms. Digestion; 61(1):6-13.

3. Kotzan J, Wade W, Yu HH (2001): Assessing NSAID prescription use as a predisposing factor for gastroesophageal reflux disease in a Medicaid population. Pharm Res.; 18(9):1367-1372.

4. Ciancarelli I, Di Massimo C, Tozzi-Ciancarelli MG, De Matteis G, Marini C, Carolei A(2002): Helicobacter pylori infection and migraine. Cephalalgia.; 22:222-225.

5. Thomas J, Straus WL, Bloom BS (2002): Over-the-counter nonsteroidal anti-inflammatory drugs and risk of gastrointestinal symptoms. Am J Gastroenterol.; 97(9):2215-2219.

6. Shaheen N, Provenzale D (2003): The epidemiology of gastroesophageal reflux disease. Am J Med Sci.; 326(5):264-273.

7. Gabrielli M, Cremonini F, Fiore G, Addolorato G, Padalino C, Candelli M, De Leo ME, Santarelli L, Giacovazzo M, Gasbarrini A, et al( 2003): Association between migraine and Celiac disease: results from a preliminary case-control and therapeutic study. Am J Gastroenterol.; 98:625-629.

8. Cicarelli G, Della Rocca G, Amboni M, Ciacci C, Mazzacca G, Filla A, Barone P(2003): Clinical and neurological abnormalities in adult celiac disease. Neurol Sci.; 24:311-317.

9. Tunca A, Türkay C, Tekin O, Kargili A, Erbayrak M(2004): Is Helicobacter pylori infection a risk factor for migraine? A case-control study. Acta Neurol Belg.; 104:161-164.

10. Vandvik PO, Wilhelmsen I, Ihlebaek C, Farup PG(2004): Comorbidity of irritable bowel syndrome in general practice: a striking feature with clinical implications. Aliment Pharmacol Ther.; 20:1195-1203.

11. Pucci E, Di Stefano M, Miceli E, Corazza GR, Sandrini G, Nappi G(2005): Patients with headache and functional dyspepsia present meal-induced hypersensitivity of the stomach. J Headache Pain.; 6:223-226.

12. Dent J, El Serag HB, Wallander MA, Johansson S (2005): Epidemiology of gastro-oesophageal reflux disease: a systematic review. Gut J Br Soc Gastroenterol.; 54(5):710-717.

13. Meucci G, Radaelli F, Prada A, Bortoli A, Crotta S, Cerrato C, Minoli G (2005): Increased prevalence of migraine in patients with uninvestigated dyspepsia referred for open-access upper gastrointestinal endoscopy. Endoscopy.; 37(7):622-625.

14. Aurora SK, Kori SH, Barrodale P, McDonald SA, Haseley D (2006): Gastric stasis in migraine: more than just a paroxysmal abnormality during a migraine attack. Headache J Head Face Pain.; 46(1):57-63.

15. Kurth T, Holtmann G, Neufang-Hüber J, Gerken G, Diener HC (2006): Prevalence of unexplained upper abdominal symptoms in patients with migraine. Cephalalgia.; 26:506-510.

16. Karamanolis G, Sifrim D (2007): Developments in pathogenesis and diagnosis of gastroesophageal reflux disease. Curr Opin Gastroenterol.; 23(4):428-433.

17. Ducrotte P, Liker HR (2007): How do people with gastro-oesophageal reflux disease perceive their disease? Results of a multinational survey. Curr Med Res Opin.; 23(11):2857-2865.

18. Yiannopoulou KG, Efthymiou A, Karydakis K, Arhimandritis A, Bovaretos N, Tzivras M(2007): Helicobacter pylori infection as an environmental risk factor for migraine without aura. J Headache Pain.; 8:329-333.

19. Aurora S, Kori S, Barrodale P, Nelsen A, McDonald S(2007): Gastric stasis occurs in spontaneous, visually induced, and interictal migraine. Headache.; 47:1443-1446.

20. Aamodt AH, Stovner LJ, Hagen K, Zwart JA (2008): Comorbidity of headache and gastrointestinal complaints. The Head-HUNT Study. Cephalalgia.; 28(2):144-151.

21. Riedl A, Schmidtmann M, Stengel A, Goebel M, Wisser AS, Klapp BF, Mönnikes H(2008): Somatic comorbidities of irritable bowel syndrome: a systematic analysis. J Psychosom Res.; 64:573-582.

22. Alehan F, Ozçay F, Erol I, Canan O, Cemil T (2008): Increased risk for coeliac disease in paediatric patients with migraine. Cephalalgia.; 28:945-949.

23. Bürk K, Farecki ML, Lamprecht G, Roth G, Decker P, Weller M, Rammensee HG, Oertel W (2009): Neurological symptoms in patients with biopsy proven celiac disease. Mov Disord.; 24:2358-2362.

24. Božena J, Katić, Wendy Golden, Roger K. Cady X. Henry Hu (2009): GERD prevalence in migraine patients and the implication for acute migraine treatment. The Journal of Headache and Pain February.; 10:(1), 35-43.

25. Lionetti E, Francavilla R, Maiuri L, Ruggieri M, Spina M, Pavone P, Francavilla T, Magistà AM, Pavone L(2009): Headache in pediatric patients with celiac disease and its prevalence as a diagnostic clue. J Pediatr Gastroenterol Nutr.; 49:202-207. 
26. Nilsson S, Edvinsson L, Malmberg B, Johansson B, Linde M (2010): A relationship between migraine and biliary tract disorders: findings in two Swedish samples of elderly twins. Acta Neurol Scand. ; 122:286-294.

27. Faraji F, Zarinfar N, Zanjani AT, Morteza A(2012): The effect of Helicobacter pylori eradication on migraine: a randomized, double blind, controlled trial. Pain Physician.; 15:495-498.

28. Benjilali L, Zahlane M, Essaadouni L(2012): A migraine as initial presentation of celiac disease. Rev Neurol (Paris); 168:454-456.

29. Yu YH, Jo Y, Jung JY, Kim BK, Seok JW (2012):Gastric emptying in migraine: a comparison with functional dyspepsia. J Neurogastroenterol Motil.; 18:412-418.

30. Yalcin H, Okuyucu EE, Ucar E, Duman T, Yilmazer S (2012): Changes in liquid emptying in migraine patients: diagnosed with liquid phase gastric emptying scintigraphy. Intern Med J.; 42:455-459.

31. Kang JW, Shin YI(2013): The role of interleukin 10 in the associations between migraine and Helicobacter pylori infection. Pain Physician.; 16:E450.

32. Chang FY, Lu CL (2013): Irritable bowel syndrome and migraine: bystanders or partners?. J Neurogastroenterol Motil.; 19:301-311.

33. Park JW, Cho YS, Lee SY, Kim ES, Cho H, Shin HE, Suh GI, Choi MG 92013): Concomitant functional gastrointestinal symptoms influence psychological status in Korean migraine patients. Gut Liver.; 7:668-674.

34. Savi L, Ribaldone DG, Fagoonee S, Pellicano R (2013). Is Helicobacter pylori the infectious trigger for headache?: A review. Infect Disord Drug Targets.; 13:313-317.

35. Aydinlar EI, Dikmen PY, Tiftikci A, Saruc M, Aksu M, Gunsoy HG, Tozun N(2013): IgG-based elimination diet in migraine plus irritable bowel syndrome. Headache.; 53:514-525.

36. Aurora SK, Papapetropoulos S, Kori SH, Kedar A, Abell TL(2013): Gastric stasis in migraineurs: etiology, characteristics, and clinical and therapeutic implications. Cephalalgia.; 33:408-415.

37. Lee KJ (2013): Gastric emptying in patients with functional dyspepsia and patients with migraine. J Neurogastroenterol Motil.; 19:116-117.

38. Parkman HP (2013): Migraine and gastroparesis from a gastroenterologist's perspective. Headache.; 53( 1):410.

39. Dimitrova AK, Ungaro RC, Lebwohl B, Lewis SK, Tennyson CA, Green MW, Babyatsky MW, Green $\mathrm{PH}$ (2013): Prevalence of migraine in patients with celiac disease and inflammatory bowel disease. Headache.; 53: $344-355$.

40. Alvarez-Arellano L, Maldonado-Bernal C (2014): Helicobacter pylori and neurological diseases: Married by the laws of inflammation. World J Gastrointest Pathophysiol.; 5:400-404.

41. Inaloo S, Dehghani SM, Hashemi SM, Heydari M, Heydari ST(2014): Comorbidity of headache and functional constipation in children: a cross-sectional survey. Turk J Gastroenterol.; 25:508-511.

42. Lau CI, Lin CC, Chen WH, Wang HC, Kao CH (2014): Association between migraine and irritable bowel syndrome: a population-based retrospective cohort study. Eur J Neurol.; 21:1198-1204.

43. Su J, Zhou XY, Zhang GX(2014): Association between Helicobacter pylori infection and migraine: a metaanalysis. World J Gastroenterol.; 20:14965-14972.11.

44. Ansari B, Basiri K, Meamar R, Chitsaz A, Nematollahi S (2015): Association of Helicobacter pylori antibodies and severity of migraine attack. Iran J Neurol.; 14:125-129.

45. Park MN, Choi MG, You SJ(2015): The relationship between primary headache and constipation in children and adolescents. Korean J Pediatr.;58:60-63.

46. Hindiyeh N, Aurora SK (2015): What the Gut Can Teach Us About Migraine. Curr Pain Headache Rep.;19:33.

47. Carlos R Cámara-Lemarroy, Rene Rodriguez-Gutierrez, Roberto Monreal-Robles, Alejandro Marfil-Rivera (2016): Gastrointestinal disorders associated with migraine: A comprehensive review. World J Gastroenterol.; 22(36): 8149-8160. 